
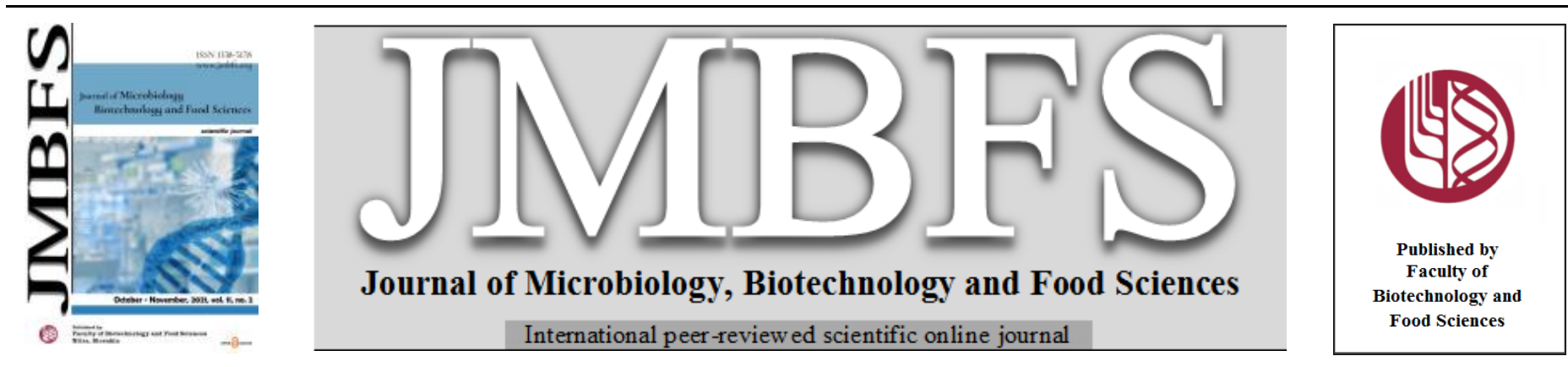

\title{
DIGESTION BY SALIVA, SIMULATED GASTRIC AND SMALL INTESTINAL JUICES AND IN VITRO FERMENTATION BY HUMAN GUT MICROBIOTA OF POLYSACCHARIDES FROM CICER ARIETINUM L. HULLS
}

\author{
Hafiz Muhammad Saleem Akhtar ${ }^{* 1}$, Mohamed Abdin ${ }^{1}$, Shakeel Ahmed ${ }^{2,3}$, Farhan Aslam ${ }^{4}$ \\ Address(es): \\ ${ }^{1}$ College of Food Science and Technology, Nanjing Agricultural University, Nanjing 210095, PR China. \\ ${ }^{2}$ Instituto de Farmacia , Facultad de Ciencias, Universidad Austral de Chile, Campus Isla Teja 509000, Valdivia, Chile. \\ ${ }^{3} \mathrm{Lab}$ of Foodomics, Institute of Food Science Research, (CIAL-CSIC), Universidad Autonoma de Madrid, Madrid, Spain. \\ ${ }^{4}$ Department of Food Science and Human Nutrition, University of Veterinary and Animal Sciences, Lahore, Pakistan.
}

*Corresponding author: saleemakhter133@gmail.com

https://doi.org/10.15414/jmbfs.3966

\section{ARTICLE INFO}

Received 15. 11.2020

Revised 18. 5. 2021

Accepted 18. 5. 2021

Published 1. 10. 2021

Regular article

open 2 access

\begin{abstract}
In the present study, digestion and fermentation (in vitro) of chickpea hull (CHPS) polysaccharides were analyzed, and CHPS effects were determined on gut microbes by using high-throughput sequencing technology. The results revealed that saliva, artificial gastric, and small intestinal juices had no effect on CHPS, but after fermentation of CHPS by human gut microbiota the molecular weight, reducing sugar and carbohydrate content decreased significantly. CHPS significantly modulated the gut microbial composition reflecting the potential to reduce obesity risk. Moreover, the decrease in $\mathrm{pH}$ was observed in the fermentation system, while short chain fatty acids (SCFAs) were significantly increased. These results indicate that CHPS have potential and could be utilized as functional food components for the improvement of human gut health.
\end{abstract}

Keywords: Cicer arietinum L.; Polysaccharide; Gut microbiota; short chain fatty acids; In vitro fermentation

\section{INTRODUCTION}

The most important organ in the human body is gastrointestinal tract (GIT) which contains mouth, oesophagus, stomach, small and large intestine (Di et al., 2018). The intake of active compounds can be broken down with the treatments of digestive enzymes, ionic strength, $\mathrm{pH}$, and microflora dispersed in GIT, and then absorbed by the epithelium of intestine. The absorptive components are moved to other target organs in the body by circulation system (Oomen et al., 2002), thus accomplishing their health advantage to modulate metabolism and fulfil nutrient requirements, diseases risk reduction(Chai et al., 2012; Lynnette \& Martin, 2007) or inhibiting infection (Roubos-van den Hil et al., 2010).

The major microbial community are found in large intestine because of suitable atmosphere, which mainly belongs to obligate anaerobes. Gut microbes offer an essential role in numerous physiologic and metabolic activities like energy production, developing and regulating the immune system, prevention of the settlement of opportunistic pathogen (Flint et al., 2012). The gut microbes are necessary for health, so it is described as the host forgotten organ (Gill et al., 2006). Though it differ among individuals, in the gut of adults mostly the microbial species could be categorized into numerous phyla: Bacteroidetes and Firmicutes, whereas Actinobacterium, Verrumicrobia and Proteobacterium, are found comparatively in lower abundance (Eckburg, 2005).

Healthful gut microbes differ with aspects such as diet, genetics, age, and environment (Di et al., 2017). It has been recommended that most individual gut microbial communities can be classified into three enterotypes based on dominant genera (Ruminococcus, Prevotella and Bacteroides) (Chen et al., 2017). The polysaccharides have several roles in life processes with comprehensive biotic activities and vast healthcare potential in cosmetics and food industries because of their efficiency and comparatively less toxic. It has been suggested that natural source polysaccharides exhibit multiple bioactivities, like antioxidant (Di et al., 2017), antitumor (He et al., 2013), antivirus (Ohta et al., 2007), antidiabetic (Guijie et al., 2016), antiobesity (Tao et al., 2016), hepatoprotective (Xu et al., 2012), anti-inflammation and immunomodulation. (Guzmán et al., 2003, Qasim et al., 2020). Several numbers of reports have shown the potential health-improving properties of polysaccharides specifically after digestion in the human body. Fuzhuan brick tea polysaccharides and from Camellia sinensis flower were not broken down by human salivary amylase but digested in simulated gastric and intestinal juices in vitro (Dan et al., 2017; Guijie et al., 2018). In our previous report, a polysaccharide from Cicer arietinum L. hull (CHPS) was prepared. Furthermore, it was found that CHPS exhibited strong scavenging activities (ABTS and DPPH). It also has reflected stronger immunostimulatory activity on RAW264.7 cells (Ye et al., 2016).

Therefore, In the current study, in vitro (digestion \& fermentation) models were applied to inspect the possible chemical and structural changes of CHPS by consecutively exposing CHPS to simulated atmospheres of mouth, stomach, small and large intestine. The CHPS effects on the gut microbes were also investigated. The goal of this study was to deliver worthwhile information about the bio-accessibility of CHPS and its potential advantage gut health.

\section{MATERIALS AND METHODS}

\section{Materials and reagents}

The (Kabuli type) Chickpea seeds were procured from the local market in Urumchi, Xinjiang Uygur, China. Bile and pancreatic salts, Trypsin (300 U $\left.\mathrm{mg}^{-1}\right)$, gastric lipase $\left(1.0 \times 105 \mathrm{U} \mathrm{g}^{-1}\right)$, pepsin $\left(3000 \mathrm{U} \mathrm{g}^{-1}\right)$, 3-Methyl-1-phenyl2-pyrazolin-5-one (PMP) were bought from Sigma Chemical Co., Ltd (USA). The standards of monosaccharides (Ara, Glc, Gal, Man, galacturonic acid (GalA), glucuronic acid (GlcA), ribose (Rib), Xyl, Fuc and Rha) were acquired from Aladdin Chemicals (Shanghai, China). 3, 5-Dinitrosalicylic acid (DNS) was obtained from Sinopharm Chemical (Shanghai, China). Inulin (INL) was a gift from Jiangmen Biological Engineering Co., Ltd (Jiangmen, China). All other used reagents were of analytical grade.

\section{Preparation of CHPS}

CHPS was prepared by following the procedure reported by (Ye et al., 2016). In short hulls were removed manually and grounded to sieve through 60 mesh. For the removal of pigments, fats (alcohol soluble) and other molecules, the chickpea hull powder was treated twice with $(80 \%)$ ethanol solution at $80^{\circ} \mathrm{C}$ for $1 \mathrm{~h}$. The obtained residue was dried and extraction was carried out two times with distilled water in a ratio of 1: 20 (material: water) $(\mathrm{w} / \mathrm{v})$ at $90{ }^{\circ} \mathrm{C}$ for $3 \mathrm{~h}$, and then combined extract was filtered and centrifuged (4000 rpm, $20 \mathrm{~min})$. Then supernatants were concentrated, mixed with a four-fold volume of absolute ethanol and kept for overnight. The obtained precipitates were mixed in deionized water, concentrated and lyophilized, affording CHPS. 


\section{Collection of human saliva}

The fresh and clear saliva was provided by four healthy volunteer without antibiotics treatment for at least three months, and had no colonic disease. The donors were also prohibited from drinking or eating prior to saliva collection for about $2 \mathrm{~h}$. Human saliva can be collected through different methods. The simplest and common method is spitting, hence used. The saliva was collected as reported by previous studies (NAVAZESH, 1993; Sari H et al., 1993; Stokes, Jason and Davies 2007)

(a) Distilled water was used for mouth rinsing by each donor to achieve a neutral mouth state for $40 \mathrm{~s}$.

(b) Saliva was spitted into the tube every $30 \mathrm{~s}$. initial $30 \mathrm{~s}$ saliva was abandoned, and for the following 2 min, saliva was collected. Then saliva was mixed from all the donors.

(C) Saliva was centrifuged immediately at $4800 \times \mathrm{g}$ for $10 \mathrm{~min}$, (to pellet the cells) and then supernatant collected and stored at $-20{ }^{\circ} \mathrm{C}$. The salivary amylase activity was determined following the method described by Van Ruth (2000).

The current study was authorized from the Ethical Committee of the Nanjing Agricultural University. All the experiments were conducted in compliance with laws as per instructed by the Chinese Government. Moreover, all the volunteers were informed priorly. All Volunteers were physically, mentally fit and were able to take part in the study.

\section{Digestion by human saliva}

Saliva digestion was conducted as described previously with minor modification (ASANO et al., 2003). Polysaccharides were dissolved $(2.0 \mathrm{mg} / \mathrm{mL})$ in distilled water. Tube A contained saliva mixture $2.0 \mathrm{~mL}$ and $2.0 \mathrm{~mL}$ of polysaccharide solution, and tube B contained $2.0 \mathrm{~mL}$ saliva mixed with water $2.0 \mathrm{~mL}$, while tube $\mathrm{C}$ had the mixture of polysaccharide $(2.0 \mathrm{~mL})$ and water $(2.0 \mathrm{~mL})$. The incubation of test tubes was carried out in a water bath for $4 \mathrm{~h}$ at $37{ }^{\circ} \mathrm{C}$. During the incubation, the samples were collected at different time intervals like 0,2 and $4 \mathrm{~h}$ respectively, then instantly immersed into a boiling water bath to deactivate the enzyme for $10 \mathrm{~min}$ and utilized for further analysis. Each experiment was repeated for three times. After digestion, the molecular weight of remaining polysaccharide was analyzed by using a high-performance liquid chromatography equipped with evaporative Light-scattering detector (HPLC-ELSD). Three replicates of each sample were collected.

\section{Gastric digestion in vitro}

The artificial gastric juice was prepared following the reported method of (Hu et al., 2013), with minor modifications. In short, gastric electrolyte solution (200.0 $\mathrm{mL}$ ) was prepared from $220.0 \mathrm{mg} \mathrm{KCl}, 120.0 \mathrm{mg} \mathrm{NaHCO}, 620.0 \mathrm{mg} \mathrm{NaCl}$, and $30 \mathrm{mg} \mathrm{CaCl}$. The $\mathrm{pH}$ of the electrolyte solution was maintained to 3.0 by using $\mathrm{HCl}$ solution $(0.1 \mathrm{M})$. Gastric juice was made up of gastric lipase $(7.5 \mathrm{mg})$, pepsin $(7.1 \mathrm{mg}), \mathrm{CH}_{3} \mathrm{COONa}$ solution $(1.0 \mathrm{M}, \mathrm{pH} 5.0,0.3 \mathrm{~mL})$ and gastric electrolyte $(30.0 \mathrm{~g})$, while the gastric juice final $\mathrm{pH}$ was modified to 3.0 by using $\mathrm{HCl}$ solution $(0.1 \mathrm{M})$. Then, $20.0 \mathrm{~mL}$ gastric juice was mixed with $20.0 \mathrm{mg}$ of CHPS and the obtained solution was incubated at $37{ }^{\circ} \mathrm{C}$ (water bath) for $6 \mathrm{~h}$ While the control (CHPS mixed in water) was also prepared under similar conditions. The reaction system $\mathrm{pH}$ was checked by using $\mathrm{pH}$ meter and modified to 3.0 by ultrapure water or $\mathrm{HCl}(1.0 \mathrm{M})$; from the incubated solution the $3.0 \mathrm{~mL}$ samples were taken out at 0,2 and $6 \mathrm{~h}$ and placed in boiled water for $10 \mathrm{~min}$ to inactivate enzyme respectively. Triplicate of each experiment was conducted.

\section{In vitro small intestinal digestion}

The intestinal artificial juice was prepared using the described method (Chen et al., 2016; Hu, et al., 2013), with a minor amendment. Briefly, $66 \mathrm{mg}$ $\mathrm{CaCl}_{2} \cdot 2 \mathrm{H}_{2} \mathrm{O}, 130 \mathrm{mg} \mathrm{KCl}$ and $1.08 \mathrm{~g} \mathrm{NaCl}$ were mixed in $500 \mathrm{~mL}$ of ultrapure water to produce the small intestinal electrolyte solution (SIE), and $1.0 \mathrm{M}$ $\mathrm{NaHCO}_{3}$ solution was used for $\mathrm{pH}$ adjustment of SIE to 7.0 . $30 \mathrm{~mL}$ ultrapure water was used to dissolve Pancreatin $2.10 \mathrm{~g}$ and then, centrifugation was done at $4000 \mathrm{rpm}$ for $10 \mathrm{~min}$. The resulting supernatant was used later. For an accurate simulation of the physiological environment of the small intestine, $100 \mathrm{~g}$ of bile salt solution $(4 \%, \mathrm{w} / \mathrm{w}), 50 \mathrm{~g}$ of pancreatin solution $(7 \%, \mathrm{w} / \mathrm{w})$, and $6.5 \mathrm{mg}$ of trypsin were mixed with $50 \mathrm{~g}$ of SIE, and $1.0 \mathrm{M} \mathrm{NaHCO}_{3}$ solution was used to obtain the final $\mathrm{pH}$ to 7.0 to obtain small intestinal juice. After gastric digestion and $\mathrm{pH}$ adjustment to 7.0 , the mixture was mixed with the small intestinal juice with a volume ratio (10:3), and then mixed solutions were incubated for $6 \mathrm{~h}$ at 37 ${ }^{\circ} \mathrm{C}$ in a water bath. During the incubation process, samples were fetched at 0,2 and $6 \mathrm{~h}$. Each experiment was repeated for three times.

\section{Preparation of fecal homogenates}

The fermentation of CHPS was analyzed by applying human gut microbes as per the reported method (Hu, et al., 2013) with several modifications. The fresh feces samples were taken from four healthy donors (one female and three males) without antibiotics usage (for at least three months) and been on normal diets.
Moreover, for the donors it's obligatory to fulfill the condition that they had not been suffered from any critical bowel disease before. The fresh random selected fecal samples were homogenized and equal quantity from each donor was mixed and then mixed well with autoclaved (PBS, 0.1 M, pH 7.2) to obtain fecal slurry $10 \%(w / v)$. For food residues removal, the supernatants were instantly placed in an anaerobic jar for further use.

\section{Fermentation in vitro by gut microbiota}

The in vitro fermentation was conceded out as per the reported method (Zhou et al., 2016). CHPS or INL (positive control) was dissolved in culture medium (10: $1, \mathrm{v} / \mathrm{w}$ ) and autoclaved. The $1.0 \mathrm{~L}$ nutrient medium of $\mathrm{pH} 7.0$ contained $0.1 \mathrm{~g}$ $\mathrm{NaCl}, 0.04 \mathrm{~g} \mathrm{KH}_{2} \mathrm{PO}_{4}, 2.0$ g yeast extract, 2.0 gm peptone, $2.0 \mathrm{gm} \mathrm{NaHCO} 3,0.01$ gm, Tween $80(2.0 \mathrm{~mL}), \mathrm{CaCl}_{2} \cdot 6 \mathrm{H}_{2} \mathrm{O}, 0.01 \mathrm{gm} \mathrm{MgSO} \cdot 7 \mathrm{H}_{2} \mathrm{O}, 0.04 \mathrm{gm} \mathrm{K}_{2} \mathrm{HPO}_{4}$, $1.0 \mathrm{mg}$ resazurin, hemin $(0.02 \mathrm{gm}), 10 \mu \mathrm{L}$ vitamin $\mathrm{K} 1$, bile salts $(0.5 \mathrm{gm})$, cysteine $\mathrm{HCl}(0.5 \mathrm{gm})$ and ultrapure water. The fermentation process was initiated by mixing $1.0 \mathrm{~mL}$ of fecal suspension with $9.0 \mathrm{~mL}$ of culture medium containing CHPS or INL and incubated at $37{ }^{\circ} \mathrm{C}$ in an anaerobic incubator (Shanghai, China). A control sample was designed by the following similar conditions, with the culture medium without adding CHPS. During the $24 \mathrm{~h}$ fermentation, the samples were collected at 0,6,12 and $24 \mathrm{~h}$, respectively, to perform further analysis. Each experiment was repeated for three times.

\section{Determination of chemical properties of CHPS}

The total carbohydrate content of CHPS was estimated by the following the reported method of phenol-sulfuric acid with Glc as the standard (DuBois et al. 1956). The DNS method was used to reduce sugar content while Glc was used as the standard (Miller, 1959). Protein content was analyzed with bovine serum albumin as the standard by following the reported method (Bradford, 1976). The uronic acid content was estimated by the reported method with GalA as the standard (Blumenkrantz \& Asboe-Hansen, 1973). The monosaccharides were determined by HPLC by following the reported method (Dai et al., 2010). $\mathrm{NaOH}$ $0.6 \mathrm{M}(100 \mu \mathrm{L})$ was mixed with a digested solution $(100 \mu \mathrm{L})$, and the obtained mixture was derivatized for $100 \mathrm{~min}$ at $70{ }^{\circ} \mathrm{C}$ with PMP $(0.5 \mathrm{M}$ methanol solution, $200 \mu \mathrm{L}$ ). After derivation, to neutralize the reaction solution $100 \mu \mathrm{L}$ of $0.3 \mathrm{M} \mathrm{HCl}$ was added. After evaporation to dryness, distilled water $1.0 \mathrm{~mL}$ was added for residue dissolving and mixing with chloroform to remove PMP. Before HPLC analysis, filtration of the solution was conducted through a $0.45 \mu \mathrm{m}$ membrane. Similarly, the monosaccharide standards were derivatized with PMP as described above. Agilent HPLC instrument (Agilent, USA) having an Eclipse Plus C18 column $(4.6 \times 250 \mathrm{~mm}, 5 \mu \mathrm{m}$, Agilent $)$ and a diode-array detector (DAD) was used to conduct HPLC analysis. The column oven temperature was set at $35^{\circ} \mathrm{C}$. As a mobile phase PBS $(0.1 \mathrm{M}, \mathrm{pH}$ 6.7) with acetonitrile at a ratio of 83: $17(\mathrm{v} / \mathrm{v})$ was utilized with flow rate of $1.0 \mathrm{~mL} / \mathrm{min}$.

\section{Determination of molecular weights}

LC-20A HPLC (Shimadzu, Japan) was used to estimate of molecular weight by using an evaporative light scattering detector (ELSD). In the current study, HPLC was connected with a TSK G4000PWXL column $(7.8 \times 300 \mathrm{~mm}$, Japan $)$ eluted at a flow rate of $0.5 \mathrm{~mL} / \mathrm{min}$ with ultrapure water while the column oven temperature was set at $35{ }^{\circ} \mathrm{C} .20 \mu \mathrm{L}$ sample volume was injected. Dextran was used as a standard for molecular weight estimation $(6.2,10,21.7,48.8,113,200$, 348 and $736 \mathrm{kDa})$

\section{Determination of SCFAs}

The assay of SCFAs was determined by following the reported method of (Ladirat et al., 2014). The centrifugation of samples was carried out for $10 \mathrm{~min}$ at $5000 \mathrm{rpm}$, and the supernatants were separated for SCFA investigation. Especially, it was executed on an Agilent $6890 \mathrm{~N}$ gas chromatography (GC) system connected with a HP-INNOWAX column $(30 \mathrm{~m} \times 0.25 \mathrm{~mm} \times 0.25 \mu \mathrm{m}$, Agilent), flame ionization detector (FID), and for the internal standard 2 ethylbutyric acid was utilized (Guijie et al., 2018). As a carrier gas Nitrogen $\left(\mathrm{N}_{2}\right)$ was provided with a total of $19.0 \mathrm{~mL} / \mathrm{min}$ flow rate. The flow rates of $\mathrm{N}_{2}$, air and hydrogen makeup gas were 30,30 and $260 \mathrm{~mL} / \mathrm{min}$, respectively. $1.0 \mu \mathrm{L}$ sample was injected. The temperature of the oven was set initially for $1 \mathrm{~min}$ at $100^{\circ} \mathrm{C}$, after that it was programmed at a speed of $5^{\circ} \mathrm{C} / \mathrm{min}$ to $180^{\circ} \mathrm{C}$ and held for $4 \mathrm{~min}$ at $180{ }^{\circ} \mathrm{C}$. The injector and detector temperature was set at $250{ }^{\circ} \mathrm{C}$. In this study, lactate was determined using a lactic acid assay kit (Nanjing, China) as per instructed guidelines of the manufacturer.

\section{Analysis of gut microbiota}

After $24 \mathrm{~h}$ of fermentation, total bacterial DNA was instantly extracted with TIANamp Stool DNA Kit (Beijing, China) as per the procedure described by manufacturers and then were stored at $-20{ }^{\circ} \mathrm{C}$. After that, It was analyzed for $16 \mathrm{~S}$ rRNA gene pyrosequencing. For each sample, the V4 region of bacteria $16 \mathrm{~S}$ 
ribosomal RNA gene was determined from Beijing Genomics Institute (Beijing, China).

\section{Statistical analysis}

Triplicates samples were performed for all the digestion experiments, and the results are prescribed as mean \pm standard deviation (SD). One-way analysis of variance (ANOVA) was applied for the comparison of multiple samples by method using SPSS 22 software (IBM). $p<0.05$ were considered statistically significant. Operational taxonomic units (OTUs) differences in relative abundance were calculated using Tukey's honest significant difference (HSD) test using the R package (https://www.r-project.org/).

\section{RESULTS AND DISCUSSION:}

The carbohydrate content of CHPS was $59.64 \pm 2.87 \%$ and the uronic acid content was $32.08 \pm 1.24 \%$, reflecting that the carbohydrate is the main component of CHPS. The protein content was $2.09 \pm 0.03 \%$. The monosaccharide composition of CHPS was; Man (2.16 mol \%), Rha $(2.96 \mathrm{~mol}$ $\%)$, GalA (32.17 mol \%), Glc (9.87 mol \%), Gal (17.21 mol \%), Xyl (6.29) and Ara $(13.38 \mathrm{~mol} \%)$.

Changes in carbohydrates, reducing sugars and monosaccharides

The results of carbohydrate contents and reducing sugars for all the samples have been shown in Table 1. For each process, all the data had been shown with $0 \mathrm{~h}$ value as a reference. There was no significant change found in the digestion process by saliva, simulated gastric and small intestinal juices.

$\underline{\text { Table } 1 \text { Total carbohydrates and reducing sugars contents during the reaction }}$

\begin{tabular}{|c|c|c|c|}
\hline Process & $\begin{array}{c}\text { Time } \\
\text { (h) }\end{array}$ & $\begin{array}{c}\text { Total } \\
\text { carbohydrates } \\
(\%)\end{array}$ & $\begin{array}{c}\text { Reducing sugars } \\
(\%)\end{array}$ \\
\hline \multirow[t]{3}{*}{ Saliva digestion } & $\mathbf{0}$ & $100.00 \pm 0.23^{a}$ & $100.00 \pm 2.91^{\mathrm{a}}$ \\
\hline & 2 & $100.25 \pm 0.39^{a}$ & $97.82 \pm 3.34^{\mathrm{a}}$ \\
\hline & 4 & $99.29 \pm 0.24^{\mathrm{a}}$ & $95.90 \pm 3.72^{\mathrm{a}}$ \\
\hline \multirow[t]{3}{*}{ Gastric Juice digestion } & $\mathbf{0}$ & $100.00 \pm 1.14^{\mathrm{a}}$ & $100.00 \pm 1.32^{\mathrm{a}}$ \\
\hline & 2 & $98.69 \pm 1.43^{\mathrm{a}}$ & $100.12 \pm 1.51^{\mathrm{a}}$ \\
\hline & 6 & $97.48 \pm 2.91^{\mathrm{a}}$ & $99.69 \pm 2.43^{\mathrm{a}}$ \\
\hline \multirow[t]{3}{*}{$\begin{array}{l}\text { Small intestinal juice } \\
\text { digestion }\end{array}$} & $\mathbf{0}$ & $100.00 \pm 1.46^{\mathrm{a}}$ & $100.00 \pm 0.51^{a}$ \\
\hline & 2 & $99.86 \pm 3.14^{\mathrm{a}}$ & $100.13 \pm 0.38^{a}$ \\
\hline & 6 & $98.71 \pm 3.27^{\mathrm{a}}$ & $99.81 \pm 1.92^{\mathrm{a}}$ \\
\hline \multirow[t]{4}{*}{$\begin{array}{l}\text { Faecal microbiota } \\
\text { fermentation }\end{array}$} & $\mathbf{0}$ & $100.00 \pm 1.27^{\mathrm{d}}$ & $100.00 \pm 3.19^{c}$ \\
\hline & 6 & $83.81 \pm 0.22^{\mathrm{c}}$ & $94.17 \pm 2.21^{\mathrm{bc}}$ \\
\hline & 12 & $72.71 \pm 0.56^{b}$ & $88.85 \pm 2.71^{b}$ \\
\hline & 24 & $58.68 \pm 1.71^{\mathrm{a}}$ & $71.17 \pm 3.93^{\mathrm{a}}$ \\
\hline
\end{tabular}

Data are presented as mean \pm standard deviations. Mean values in the same column with different letters were significantly different $(p<0.05)$

While during the fermentation process by gut microbiota, a significant decrease was observed in reducing sugar and total carbohydrates contents. So it was preliminarily concluded that CHPS was not digested by mouth, stomach and small intestine. However, no free monosaccharide was produced $(\mathbf{F i g} . \mathbf{1 A}, \mathbf{B}, \mathbf{C})$ from CHPS during the whole digestion process. The results of the current study are aligned with Ding et al. (2017) where polysaccharide from Ganoderma atrum was evaluated in gastrointestinal digestion and fermentation.

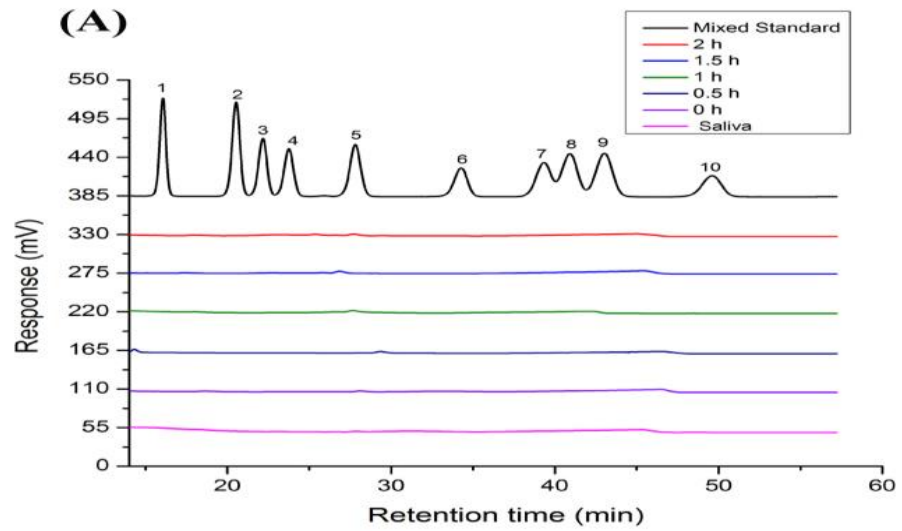

\section{(B)}
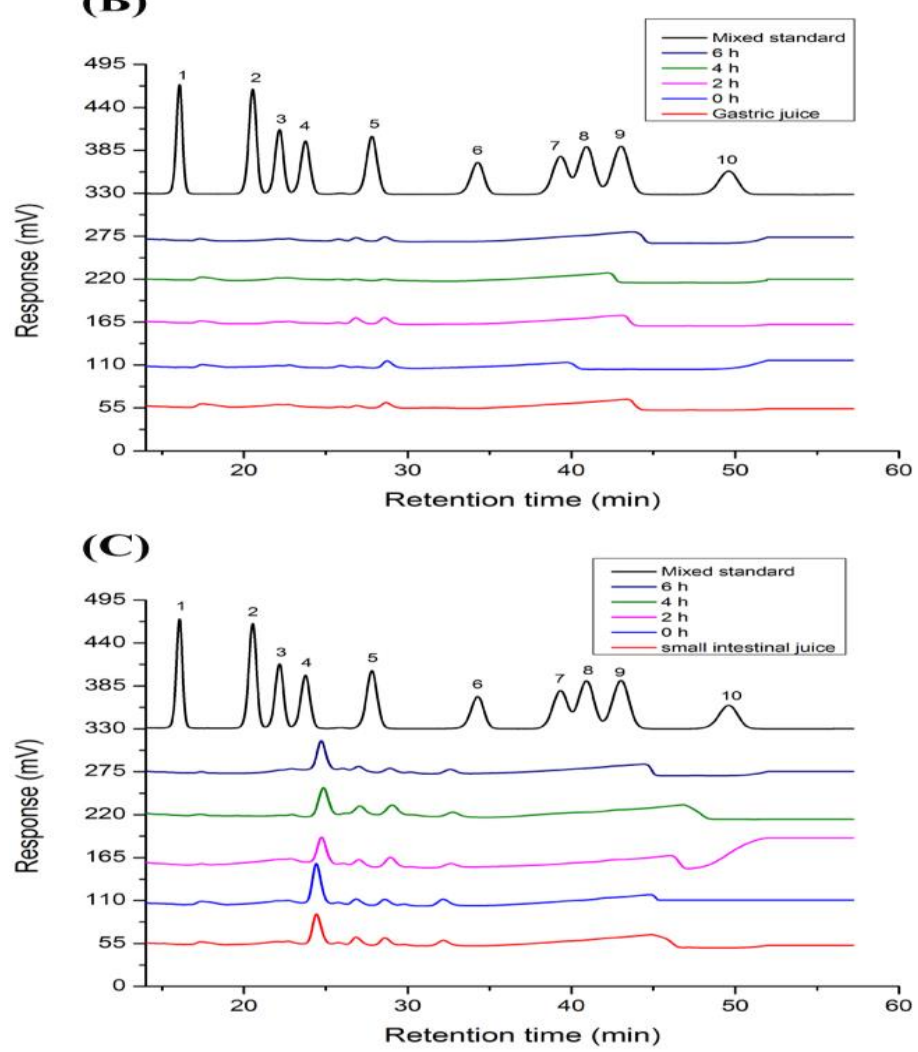

Figure 1 The chromatogram profiles of monosaccharide composition of CHPS (a), before and after artificial simulated saliva (b), gastric (c) small intestinal digestion. Peaks followed by the orders: 1, Man; 2, Rib; 3, Rha; 4, GlcA; 5, GalA; 6, Glc; 7, Gal; 8, Xyl; 9, Ara; 10, Fuc.

\section{Molecular weight changes in CHPS}

In the present study, the amylase activity of saliva was estimated $125 \pm 4 \mathrm{D}$ units/mL, which was found to be in the normal range of salivary amylase activity (18-208 D units/mL) according to previously reported data by van Ruth. (2000). It has been depicted in Fig. 2A, B that there was no significant difference observed in the molecular weight of CHPS after saliva digestion, describing that CHPS was not broken down by human saliva. As no change detected in the CHPS retention time after digestion with the simulated gastric or small intestinal juices (Fig. 2C, D and E, F), suggesting that CHPS was also not broken down in the process, which is in agreement with a previous report (Carnachan et al., 2012). 

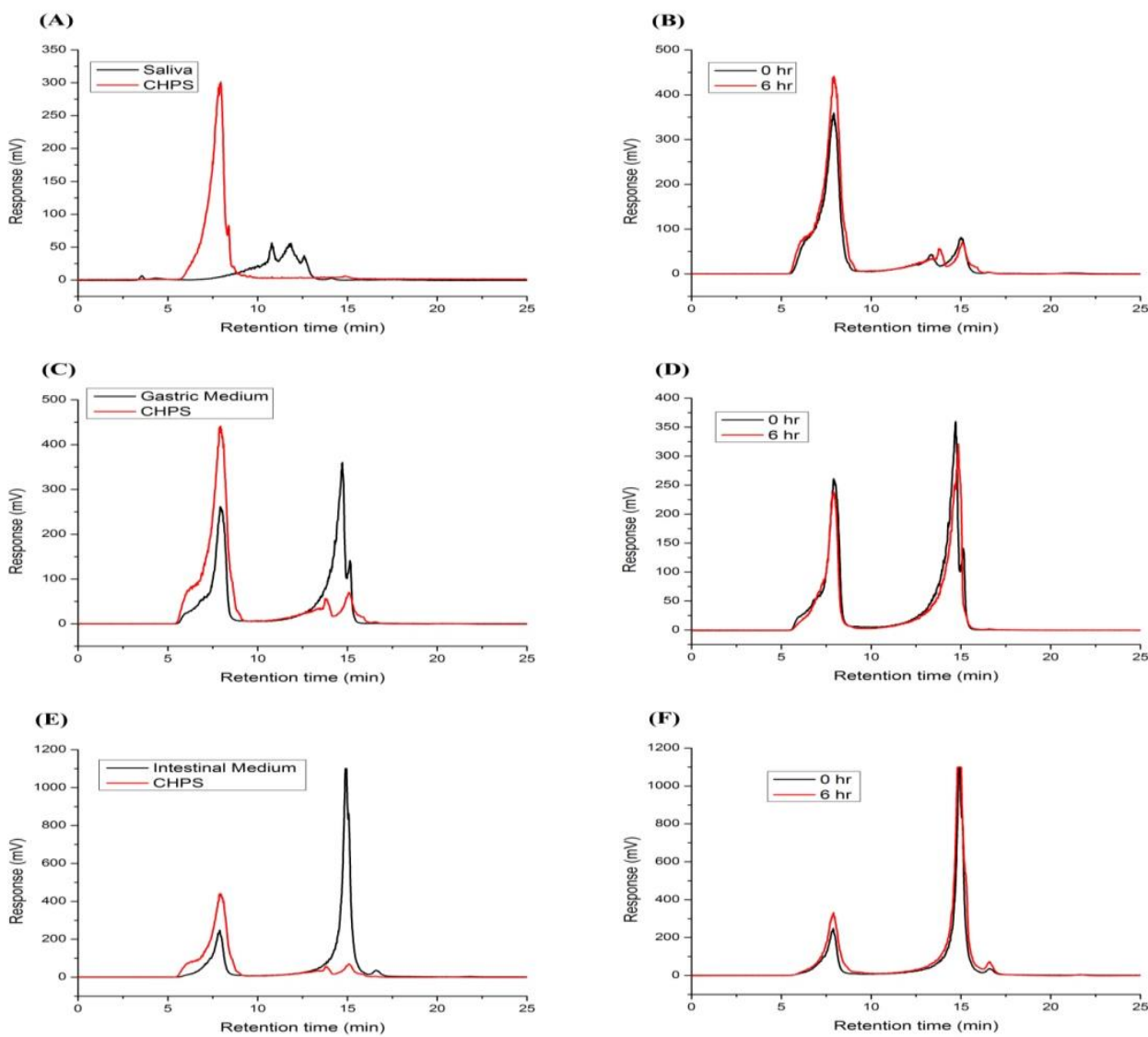

Figure 2 HPGPC chromatograms of CHPS before and after saliva (a and b), simulated gastric ( $c$ and d) and small intestinal (e and f) digestion.

After in vitro fermentation of CHPS by gut microbes as has been shown in Fig. $\mathbf{3 A}$ and $\mathbf{B}$ it was evaluated for possible molecular weight change at different time intervals of $(6,12,24 \mathrm{~h})$. It was a response of CHPS in HPLC significantly decreased with an increase in fermentation time.

(A)

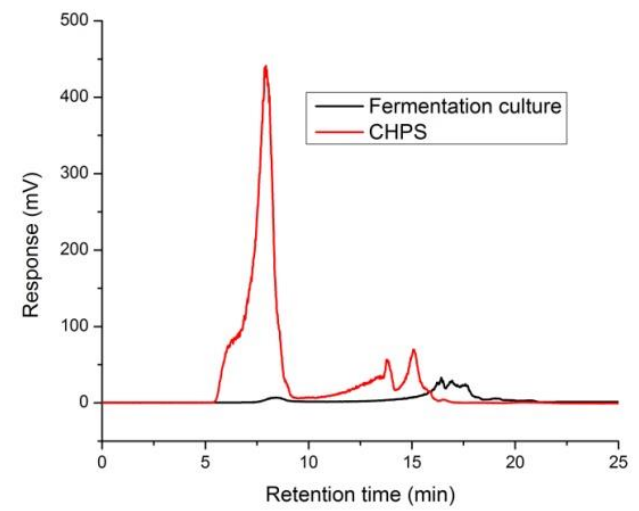

Specifically, at the retention time of about $21 \mathrm{~min}$ a small peak appeared after 12 and $24 \mathrm{~h}$ of fermentation, mentioning that CHPS could be hydrolyzed by the gut microbiota to smaller molecular weights fragments during in vitro fermentation process. The result described that CHPS could be hydrolyzed by the gut microbiota to the fragments of smaller molecular weights. It was in consistent with the decrease in reducing sugars and total carbohydrates.

(B)

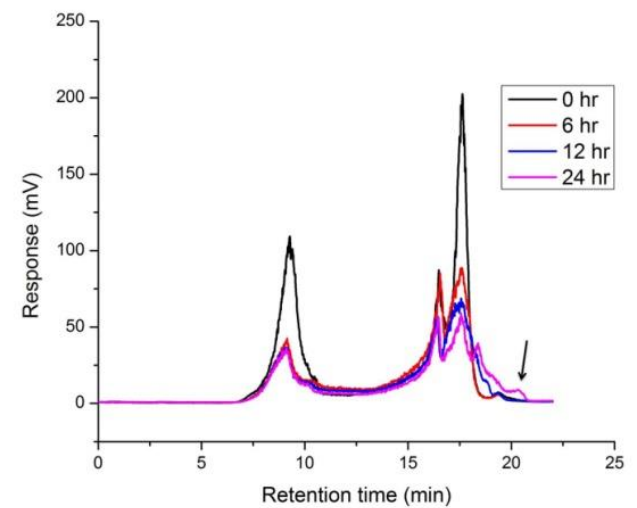

Figure 3 HPGPC chromatograms of CHPS before and after fermentation by human gut microbiota.

\section{Effect of CHPS on gut microbiota}

The human faecal microbiota plays a very important role in human health Previous studies have described various functional features of the gut microbiota, such as synthesis of essential amino acids and vitamins, fermentation of indigestible dietary polysaccharides and xenobiotic drugs metabolism (Cabreiro et al., 2013; Chang et al., 2015). The gut microbial composition is related to acquiring the nutrient and energy regulation (Schloss et al., 2009). The relations among bacterial metabolites, gut microbiota and CHPS could be advantageous for disease prevention and health promotion through modulation of gut microbiota.

Therefore, the CHPS effect on gut microbiota was explored by using analysis of high throughput sequencing. After selecting the usable reads from 20 samples a total of 218, 9397 effective reads were obtained with the average of $109469 \pm$ 46257 reads for each sample ( $n=5$ for each group). Principal component analysis (PCA) scores plot was applied to analyze the distinct clustering of gut microbiome compositions from various samples based on OTUs (Fig. 4A). The first two principal coordinates revealed $92.45 \%$ of the inter-sample variance total (PC1: $63.95 \%$ and $\mathrm{PC} 2: 28.50 \%$ ), suggesting that the microbial structure displayed an evident change in response to CHPS fermentation. It was also confirmed by the results of Bray-Curtis clustering analysis at OTUs level (Fig. 4B). Besides, in a group the gut microbial communities of samples were more similar to each other as compared to other groups.

Alpha diversity was applied to analyze the complexity of species diversity for each sample. The observed species index can be utilized for richness determination of communities, while the Shannon index is typically associated 
with evaluating species diversity (Paulson et al., 2011). The results of alpha diversity and Shannon index has been depicted in Fig. 4C and D respectively. The Shannon index complexity of the sample was comparable to the values of observed species. Based on the value of the Shannon index and amount of OTUs,

(A)

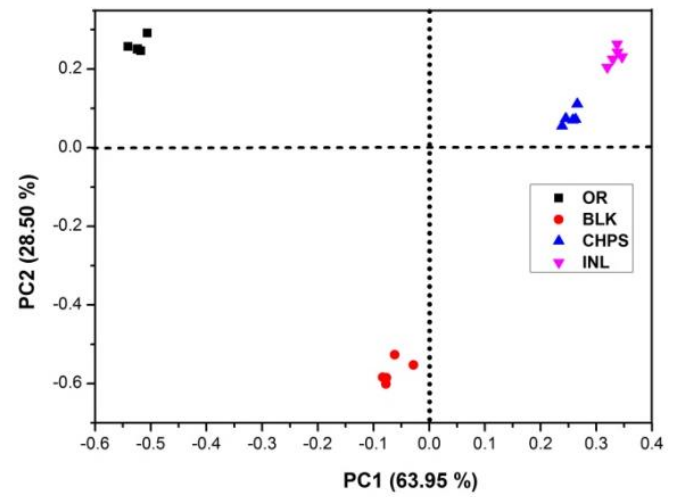

(C)

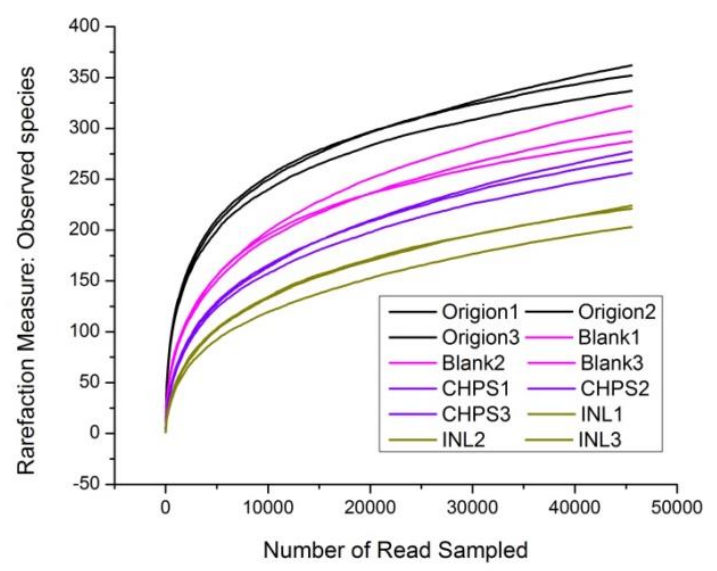

alpha diversity analysis demonstrated that in the present study the sequencing process has covered maximum bacterial species and can accurately illustrate the microbial community of samples.

(B)

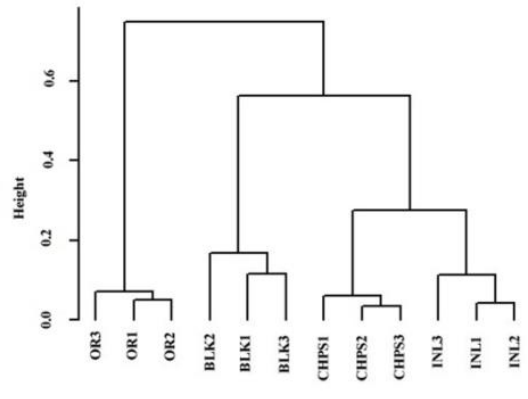

(D)

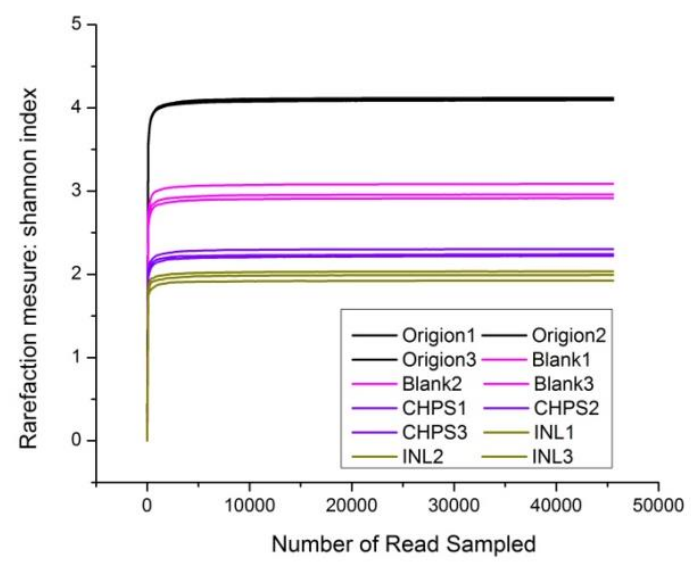

Figure 4 Compositions of gut microbiota. (a) Principal component analysis of gut microbiota at the OUT level, (b) Multivariate analysis of variance from matrix scores based on Bray-Curtis method, (c) $\alpha$ diversity indices (d) Shannon index.

LEfSe analysis, which is an authentic statistical method designed to compare for the microbial community based on 16S rRNA abundance data, which was then applied to explicit and demonstrate the bacterial characteristics for each treatment (Garcia-Mazcorro et al., 2017). The present study results verified that most of these trends displayed significant association by adding of CHPS or not. During the comparison of intra-group variance at OTUs level applying linear discriminant analysis conjugated with effect size (LEfSe) reflected that a total of 46 OTUs were significantly different $(p<0.05)$ in three groups (Fig. 5A) Although, 30 OTUs in Blank group, 7 OTUs in the INL group and 9 OTUs in CHPS group were higher based on LDA scores (log 10) respectively.

The relative abundance of OTU004 (Megamonas) significantly increased in the INL group reflecting that it is dominant and may be principal gut microbe to hydrolyze and utilize INL. It has been described that INL involvement can significantly produce higher abundance of Megamonas ( Guijie et al., 2018). A the same time, OTU010 (Megasphaera) was also noticed with a higher relative abundance. Actinobacteria of genus Bifido-bacterium (OTU006) which are distinctive probiotics which are involved in gut health (G. D. Wu et al., 2011), accumulated in the INL treatment group. However, bifido-bacterium was not noticed in the Blank and CHPS groups. Ruminococcaceae (OTU022) has been verified to incorporate with the Bacteroides partialy, so it enhanced with the enrichment of Bacteroides after CHPS fermentation (De Filippo et al., 2010).
Furthermore, the CHPS group showed Prevotella (OTU333) enrichment, which is always examined with the hydrolysis of indigestible carbohydrate (KovatchevaDatchary et al., 2015). Increased Prevotella can enhance the glucose breakdown, which plays a significant role in the advantageous response (Ndeh et al., 2017). These observations are in agreement with earlier findings that Bacteroides have diverse effects on glycan. Bacteroides was observed to generate numerous glycoside hydrolases to utilize and metabolize complex dietary glycans. Consequently, the glycan would promote the strain's growth ( Guijie et al. 2018). Moreover, Bacteroides play significant role to maintain microflora, which is linked with anti-inflammation. The studies have recommended that both Bacteroides and Prevotella are two kinds of advantageous gut microbes. Furthermore, the increasing number of confirmations has shown that the gut microbes contributing to the degradation of indigestible dietary polysaccharides might be improved (Ríos-Covián et al., 2016). Thus, Bacteroides and Prevotella could be two important members of gut microbes for use and hydrolysis of CHPS. CHPS also possessed the property for enhancing SCFAs production and declining $\mathrm{pH}$, hence found helpful for modulating the structure of microbiota. Overall, these results demonstrate that CHPS fermentation modified the structure of microbes and improved several bacteria that can depolymerize and digest polysaccharide to obtain energy from CHPS and to fulfill gut microbial growth. 
(A)

(B)

(C)
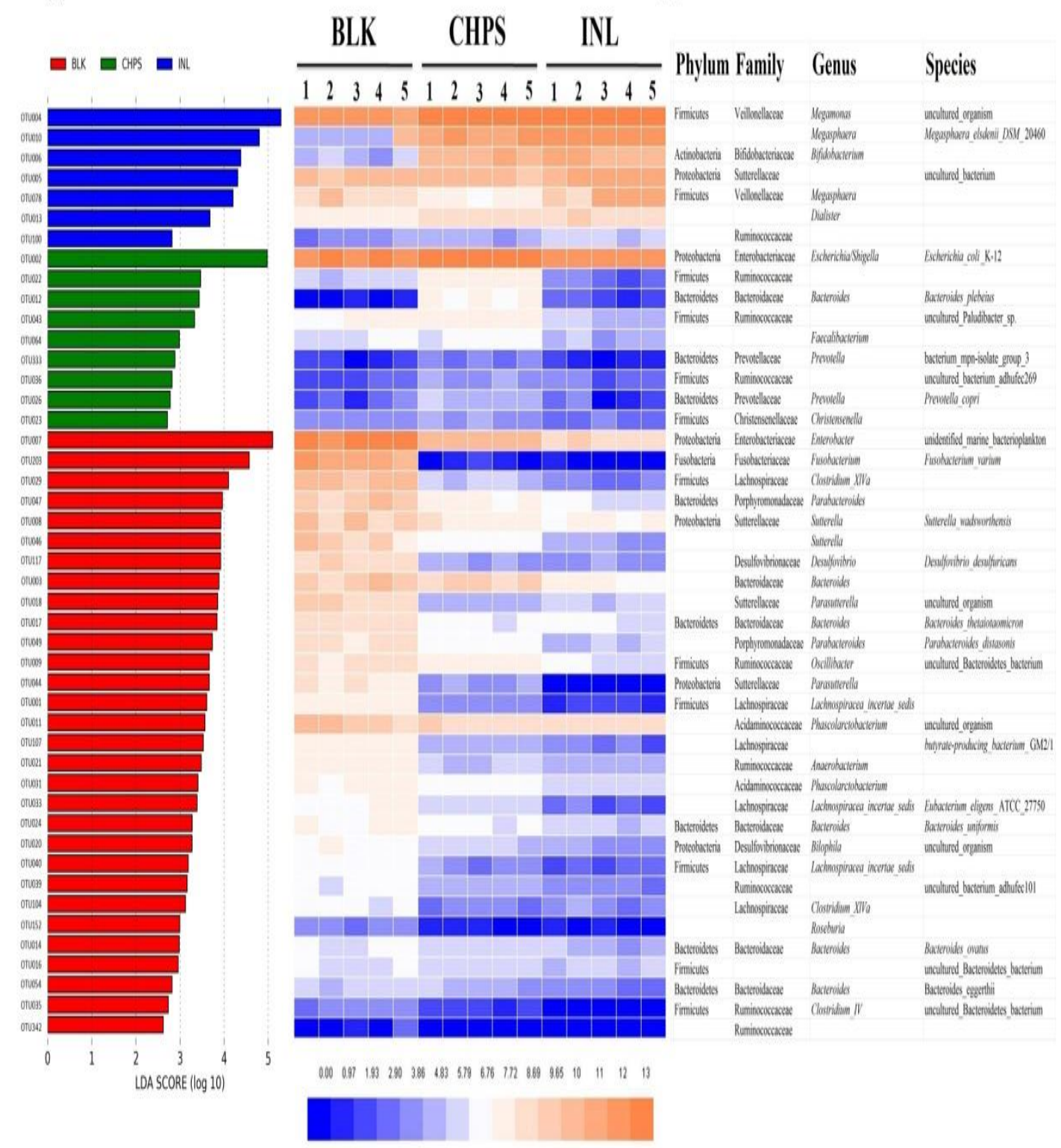

Figure 5 Comparison of gut microbiota using LEfSe among Blank, CHPS and INL groups at OTUs level. (a) Histogram of LDA scores computed for feature differentially abundant, (b) Heatmaps of gut bacteria with the relative abundance (log 10 transformation) of OTUS based on the result of LEfSe, (c) Represented bacterial taxa information including phylum, family, genus and species.

\section{Production of SCFAs in vitro fermentation}

During the fermentation process gut microbes produce SCFAs as products which are volatile. These are produced in the large bowel from dietary substances which are indigestible in the small intestine. These could be deposited as a source of energy and decrease the osmotic pressure after being quickly consumed by the intestine, which have an essential role to maintain the typical function of the large intestine and epithelial cells of colon (Sonnenburg et al., 2010). Former reports have shown the importance of SCFAs promoting colonocyte health and ameliorating chronic inflammatory diseases (Neyrinck et al., 2011). It has been proved that by the fermentation of prebiotics and polysaccharides with gut microbes like the genus Bacteroides might produce SCFAs (Fernández et al. 2016). The SCFAs concentrations are measured as significant considerations of gut microbial action (Tremaroli \& Bäckhed, 2012). As shown in Table 2 the total SCFAs in all samples enhanced with fermentation.

In CHPS group, the initial total SCFAs concentration was $31.63 \pm 4.23 \mathrm{mmol} / \mathrm{L}$ which increased to $40.76 \pm 3.94 \mathrm{mmol} / \mathrm{L}$ at $24 \mathrm{~h}$, greater than that of a blank group $(23.37 \pm 3.89 \mathrm{mmol} / \mathrm{L})$ and $\mathrm{INL}$ group $(47.97 \pm 8.19 \mathrm{mmol} / \mathrm{L})$, demonstrating that CHPS had supporting effect on SCFAs production. During the comprehensive analysis of SCFAs in the CHPS group reflected that isobutyric, acetic and propionic acids were principal fermentation products and their final concentrations were considerably higher as compared in blank group. Acetic acid

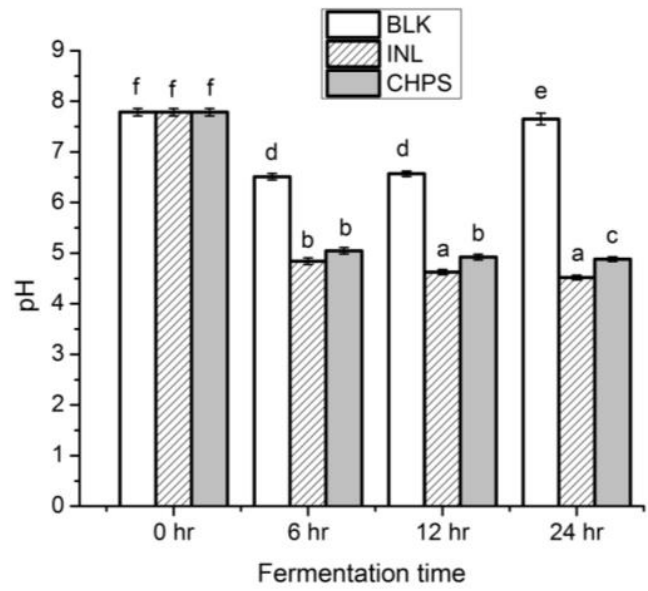

Figure $6 \mathrm{pH}$ changes in fermented cultures added with CHPS or INL or without addition (control) at different times during fermentation. Different letters mean significantly different $(p<0.05)$ from each other. 
concentration at $24 \mathrm{~h}$ was $16.26 \pm 1.29 \mathrm{mmol} / \mathrm{L}$, but propionic acid was in second place with a concentration of $11.30 \pm 0.56 \mathrm{mmol} / \mathrm{L}$. The n-butyric acid final concentration was found at $3.68 \pm 0.29 \mathrm{mmol} / \mathrm{L}$. Propionic and acetic acids are recognized as a source of energy for peripheral and liver issues, which could be absorbed by the wall of the colon, then through circulatory system moved to target organs for energy provision. They have significant roles in lipogenesis and gluconeogenesis (Gulfi et al., 2007; Zambell et al., 2003). The quantities of isovaleric and valeric acids also presented an important difference than those of blank group. The butyric acid concentration was higher compared to a blank group.

\section{Effects of CHPS on pH}

During the fermentation process, $\mathrm{pH}$ change is considered as a main and important indication. The average value of the initial $\mathrm{pH}$ of mixed cultures was
7.78. After $6 \mathrm{~h}$ incubation, a significant reduction of $\mathrm{pH}$ (from 7.78 to 4.88 ) was noticed for the fermentation of CHPS than those of control (Fig. 6). Though, during the fermentation time (6 to $24 \mathrm{~h}$ ), the $\mathrm{pH}$ of each group declined. During the whole fermentation process, the $\mathrm{pH}$ of the CHPS group was lower as compared to the control group at a similar fermentation time. Additionally, the CHPS group $\mathrm{pH}$ value was observed closer to that of the INL group, which could be associated with an increased level of SCFAs production (Table 2).

Different researches have described that the decline of $\mathrm{pH}$ is due to fermentation of the polysaccharides. The current study observations are in agreement with (Gulfi et al., 2007) where it was revealed that $\mathrm{pH}$ value decreased in vitro fermented pectin with fresh human excretal microbes. Hu et al. (Hu et al., 2013) have described the similar behaviour where polysaccharides of centella asiatica L. showed an effect on declining $\mathrm{pH}$ value with the fermentation of human gut microbiota

Table 2 Concentrations of SCFAs (mmol/L) in fermentation solutions at different time points

\begin{tabular}{|c|c|c|c|c|c|c|c|c|c|}
\hline Treatment & $\begin{array}{c}\text { Time } \\
\text { (h) }\end{array}$ & Acetic Acid & $\begin{array}{c}\text { Propionic } \\
\text { acid }\end{array}$ & $\begin{array}{c}\text { i-Butyric } \\
\text { acid }\end{array}$ & $\begin{array}{c}\text { n-Butyric } \\
\text { acid }\end{array}$ & $\begin{array}{c}\text { i-Valeric } \\
\text { acid }\end{array}$ & $\begin{array}{l}\text { n-Valeric } \\
\text { acid }\end{array}$ & Lactic acid & Total \\
\hline \multirow[t]{4}{*}{ Blank } & 0 & nd & nd & $\mathrm{Nd}$ & nd & nd & nd & nd & nd \\
\hline & 6 & $5.79 \pm 0.74^{\mathrm{b}}$ & $3.00 \pm 0.21^{\mathrm{b}}$ & $\mathrm{Nd}$ & $0.52 \pm 1.18^{\mathrm{a}}$ & nd & nd & $1.03 \pm 0.2^{\mathrm{c}}$ & $10.34 \pm 2.35^{\mathrm{b}}$ \\
\hline & 12 & $8.81 \pm 1.25^{\mathrm{c}}$ & $4.51 \pm 0.42^{\mathrm{c}}$ & $0.67 \pm 0.0^{\mathrm{b}}$ & $0.96 \pm 0.12^{\mathrm{ab}}$ & $0.86 \pm 0.04^{\mathrm{b}}$ & nd & $0.42 \pm 0.0^{\mathrm{b}}$ & $16.23 \pm 1.89^{b}$ \\
\hline & 24 & $10.05 \pm 1.5^{\mathrm{c}}$ & $4.69 \pm 0.44^{\mathrm{c}}$ & $0.75 \pm 0.1^{\mathrm{b}}$ & $2.02 \pm 0.08^{\mathrm{b}}$ & $1.42 \pm 0.96^{\mathrm{c}}$ & $4.11 \pm 0.71^{\mathrm{b}}$ & $0.33 \pm 0.0^{\mathrm{b}}$ & $23.37 \pm 3.89^{c}$ \\
\hline
\end{tabular}

CHPS

$\begin{array}{ccc}0 & \text { nd } & \text { nd } \\ 6 & 12.97 \pm 2.6^{\mathrm{b}} & 10.48 \pm 1.3^{\mathrm{b}} \\ 12 & 16.07 \pm 5.1^{\mathrm{b}} & 11.61 \pm 2.3^{\mathrm{b}} \\ 24 & 16.26 \pm 1.2^{\mathrm{b}} & 11.30 \pm 0.5^{\mathrm{b}}\end{array}$

$\begin{array}{cc}\mathrm{Nd} & \mathrm{nd} \\ \mathrm{Nd} & -0.18 \pm 0.03^{\mathrm{a}} \\ 0.70 \pm 0.0^{\mathrm{b}} & 2.35 \pm 0.45^{\mathrm{b}} \\ 0.78 \pm 0.0^{\mathrm{b}} & 3.68 \pm 0.29^{\mathrm{c}}\end{array}$

$\begin{array}{cc}\text { nd } & \text { nd } \\ \text { nd } & 3.57 \pm 0.00^{\mathrm{a}} \\ 1.31 \pm 0.86^{\mathrm{b}} & 5.77 \pm 2.31^{\mathrm{b}} \\ 1.79 \pm 0.43^{\mathrm{b}} & 6.58 \pm 1.21^{\mathrm{b}}\end{array}$

nd

$4.79 \pm 0.2^{\mathrm{c}}$

nd

$1.05 \pm 0.1^{\mathrm{b}} \quad 38.86 \pm 11.4^{\mathrm{b}}$

$31.63 \pm 4.23^{\mathrm{b}}$

$0.37 \pm 0.1^{\mathrm{a}} \quad 40.76 \pm 3.94^{\mathrm{b}}$

INL

$\begin{array}{cccc}0 & \text { nd } & \text { nd } & \mathrm{Nd} \\ 6 & 11.29 \pm 1.2^{\mathrm{a}} & 10.17 \pm 0.8^{\mathrm{b}} & \mathrm{Nd} \\ 12 & 19.80 \pm 1.1^{\mathrm{b}} & 13.60 \pm 0.6^{\mathrm{c}} & \mathrm{Nd} \\ 24 & 19.55 \pm 3.7^{\mathrm{b}} & 10.46 \pm 1.2^{\mathrm{b}} & 0.70 \pm 0.0^{\mathrm{b}}\end{array}$

nd
$-0.02 \pm 0.17^{\mathrm{a}}$
$5.17 \pm 0.16^{\mathrm{b}}$
$8.34 \pm 1.34^{\mathrm{c}}$

$\begin{array}{cc}\text { nd } & \text { nd } \\ \text { nd } & 3.61 \pm 0.00^{\mathrm{a}} \\ 0.69 \pm 0.04^{\mathrm{b}} & 5.10 \pm 0.40^{\mathrm{b}} \\ 1.04 \pm 0.22^{\mathrm{c}} & 7.42 \pm 1.49^{\mathrm{b}}\end{array}$

nd
$4.04 \pm 0.2^{\mathrm{c}}$
$0.73 \pm 0.0^{\mathrm{b}}$
$0.46 \pm 0.1^{\mathrm{b}}$

nd

$29.09 \pm 2.53^{\mathrm{b}}$

$45.09 \pm 2.38^{\mathrm{c}}$

$47.97 \pm 8.19^{\mathrm{c}}$

SCFAs, short-chain fatty acids; CHPS, chickpea hull polysaccharides; INL, Inulin; nd, not detected

a-c: Mean value in same column with different letters was significantly different from each other $(p<0.05)$ by Tukey test

\section{CONCLUSION}

In this study, CHPS were not decomposed with saliva, artificial gastric and small intestinal juices in simulated digestion models. Though, after fermentation, molecular weight, total carbohydrate and reducing sugars of CHPS declined significantly by the human gut microbiota. While, $16 \mathrm{~S}$ rRNA gene amplification investigation recommended that CHPS raised the growth of advantageous microbes specifically Bacteroides and Prevotella. Furthermore, in the fermentation system SCFAs production enhanced. These observations provided insights into the digestive and fermentation attributes of CHPS in vitro. The results presented here recommend that CHPS have the potential as a functional ingredient for gut health promotion.

Acknowledgements: The present work was partially supported by a project funded by the Priority Academic Program Development of Jiangsu Higher Education Institutions. The first author would like to express his thanks to the Ministry of Education of China for financial assistance through the Chinese Government Scholarship Program.

\section{REFERENCES}

ASANO, I., HAMAGUCHI, K., FUJII, S., \& IINO, H. (2003). In Vitro Digestibility and Fermentation of Mannooligosaccharides from Coffee Mannan. Food Science and Technology Research, 9(1), 62-66. https://doi.org/10.3136/fstr.9.62

Blumenkrantz, N., \& Asboe-Hansen, G. (1973). New method for quantitative determination of uronic acids. Analytical Biochemistry, 54(2), 484-489. https://doi.org/10.1016/0003-2697(73)90377-1

Bradford, M. M. (1976). A rapid and sensitive method for the quantitation of microgram quantities of protein utilizing the principle of protein-dye binding. Analytical Biochemistry, 72(1-2), 248-254. https://doi.org/10.1016/00032697(76)90527-3

Cabreiro, F., Au, C., Leung, K.-Y., Vergara-Irigaray, N., Cochemé, H. M., Noori, T., Weinkove, D., Schuster, E., Greene, N. D. E., \& Gems, D. (2013). Metformin Retards Aging in C. elegans by Altering Microbial Folate and Methionine Metabolism. Cell, 153(1), 228-239. https://doi.org/10.1016/j.cell.2013.02.035

Carnachan, S. M., Bootten, T. J., Mishra, S., Monro, J. A., \& Sims, I. M. (2012). Effects of simulated digestion in vitro on cell wall polysaccharides from kiwifruit (Actinidia spp.). Food Chemistry, 133(1), 132-139. https://doi.org/10.1016/j.foodchem.2011.12.084

Chai, S. C., Hooshmand, S., Saadat, R. L., Payton, M. E., Brummel-Smith, K., \& Arjmandi, B. H. (2012). Daily Apple versus Dried Plum: Impact on Cardiovascular Disease Risk Factors in Postmenopausal Women. Journal of the Academy of Nutrition and Dietetics, 112(8), 1158-1168. https://doi.org/10.1016/j.jand.2012.05.005

Chang, C.-J., Lin, C.-S., Lu, C.-C., Martel, J., Ko, Y.-F., Ojcius, D. M., Tseng, S.-F., Wu, T.-R., Chen, Y.-Y. M., Young, J. D., \& Lai, H.-C. (2015). Ganoderma lucidum reduces obesity in mice by modulating the composition of the gut microbiota. Nature Communications, 6(1), 7489. https://doi.org/10.1038/ncomms8489

Chen, C., Zhang, B., Fu, X., You, L.-J., Abbasi, A. M., \& Liu, R. H. (2016). The digestibility of mulberry fruit polysaccharides and its impact on lipolysis under simulated saliva, gastric and intestinal conditions. Food Hydrocolloids, 58, 171-178. https://doi.org/10.1016/i.foodhyd.2016.02.033

Chen, D., Chen, G., Wan, P., Hu, B., Chen, L., Ou, S., Zeng, X., \& Ye, H. (2017). Digestion under saliva, simulated gastric and small intestinal conditions and fermentation in vitro of polysaccharides from the flowers of Camellia sinensis induced by human gut microbiota. Food \& Function, 8(12), 4619-4629. https://doi.org/10.1039/C7FO01024A

Chen, G., Xie, M., Wan, P., Chen, D., Ye, H., Chen, L., Zeng, X., \& Liu, Z. (2018) Digestion under saliva, simulated gastric and small intestinal conditions and fermentation in vitro by human intestinal microbiota of polysaccharides from Fuzhuan $\begin{array}{llll}\text { brick } & \text { Food } & \text { Chemistry, 244, 331-339. }\end{array}$ https://doi.org/10.1016/j.foodchem.2017.10.074

Chen, G., Yuan, Q., Saeeduddin, M., Ou, S., Zeng, X., \& Ye, H. (2016). Recent advances in tea polysaccharides: Extraction, purification, physicochemical characterization and bioactivities. Carbohydrate Polymers, 153, 663-678. https://doi.org/10.1016/j.carbpol.2016.08.022

Chen, L., Xu, W., Chen, D., Chen, G., Liu, J., Zeng, X., Shao, R., \& Zhu, H. (2018). Digestibility of sulfated polysaccharide from the brown seaweed Ascophyllum nodosum and its effect on the human gut microbiota in vitro. International Journal of $\begin{array}{lll}\text { Biological Macromolecules, } & 112, & 1055-1061 .\end{array}$ https://doi.org/10.1016/j.ijbiomac.2018.01.183

Dai, J., Wu, Y., Chen, S., Zhu, S., Yin, H., Wang, M., \& Tang, J. (2010). Sugar compositional determination of polysaccharides from Dunaliella salina by modified RP-HPLC method of precolumn derivatization with 1-phenyl-3-methyl-5-pyrazolone. Carbohydrate Polymers,
https://doi.org/10.1016/j.carbpol.2010.05.029

De Filippo, C., Cavalieri, D., Di Paola, M., Ramazzotti, M., Poullet, J. B., Massart, S., Collini, S., Pieraccini, G., \& Lionetti, P. (2010). Impact of diet in shaping gut microbiota revealed by a comparative study in children from Europe and rural Africa. Proceedings of the National Academy of Sciences, 107(33), 14691-14696. https://doi.org/10.1073/pnas.1005963107

Di, T., Chen, G., Sun, Y., Ou, S., Zeng, X., \& Ye, H. (2017). Antioxidant and immunostimulating activities in vitro of sulfated polysaccharides isolated from Gracilaria rubra. Journal of Functional Foods, 28, 64-75. https://doi.org/10.1016/j.jff.2017.10.040

Di, T., Chen, G., Sun, Y., Ou, S., Zeng, X., \& Ye, H. (2018). In vitro digestion by saliva, simulated gastric and small intestinal juices and fermentation by human fecal 
microbiota of sulfated polysaccharides from Gracilaria rubra. Journal of Functional Foods, 40, 18-27. https://doi.org/10.1016/j.jff.2016.11.005

Ding, Q., Nie, S., Hu, J., Zong, X., Li, Q., \& Xie, M. (2017). In vitro and in vivo gastrointestinal digestion and fermentation of the polysaccharide from Ganoderma $\begin{array}{llll}\text { atrum. } & \text { Food Hydrocolloids, 63, 646-655. }\end{array}$ https://doi.org/10.1016/j.foodhyd.2016.10.018

DuBois, M., Gilles, K. A., Hamilton, J. K., Rebers, P. A., \& Smith, F. (1956). Colorimetric Method for Determination of Sugars and Related Substances. Analytical Chemistry, 28(3), 350-356. https://doi.org/10.1021/ac60111a017

Eckburg, P. B. (2005). Diversity of the Human Intestinal Microbial Flora. Science, 308(5728), 1635-1638. https://doi.org/10.1126/science.1110591

Fernández, J., Redondo-Blanco, S., Gutiérrez-del-Río, I., Miguélez, E. M., Villar, C. J., \& Lombó, F. (2016). Colon microbiota fermentation of dietary prebiotics towards short-chain fatty acids and their roles as anti-inflammatory and antitumour agents: A review. Journal of Functional Foods, 25, 511-522. https://doi.org/10.1016/j.jff.2016.06.032

Flint, H. J., Scott, K. P., Louis, P., \& Duncan, S. H. (2012). The role of the gut microbiota in nutrition and health. Nature Reviews Gastroenterology \& Hepatology, 9(10), 577-589. https://doi.org/10.1038/nrgastro.2012.156

Garcia-Mazcorro, J. F., Barcenas-Walls, J. R., Suchodolski, J. S., \& Steiner, J. M. (2017). Molecular assessment of the fecal microbiota in healthy cats and dogs before and during supplementation with fructo-oligosaccharides (FOS) and inulin using highthroughput 454-pyrosequencing. PeerJ, 5, e3184. https://doi.org/10.7717/peerj.3184 Gill, S. R., Pop, M., DeBoy, R. T., Eckburg, P. B., Turnbaugh, P. J., Samuel, B. S., Gordon, J. I., Relman, D. A., Fraser-Liggett, C. M., \& Nelson, K. E. (2006) Metagenomic Analysis of the Human Distal Gut Microbiome. Science, 312(5778), 1355-1359. https://doi.org/10.1126/science.1124234

Gulfi, M., Arrigoni, E., \& Amadò, R. (2007). In vitro fermentability of a pectin fraction rich in hairy regions. Carbohydrate Polymers, 67(3), 410-416. https://doi.org/10.1016/j.carbpol.2006.06.018

Guzmán, S., Gato, A., Lamela, M., Freire-Garabal, M., \& Calleja, J. M. (2003). Antiinflammatory and immunomodulatory activities of polysaccharide from Chlorella stigmatophora and Phaeodactylum tricornutum. Phytotherapy Research, 17(6), 665670. https://doi.org/10.1002/ptr.1227

He, N., Shi, X., Zhao, Y., Tian, L., Wang, D., \& Yang, X. (2013). Inhibitory Effects and Molecular Mechanisms of Selenium-Containing Tea Polysaccharides on Human Breast Cancer MCF-7 Cells. Journal of Agricultural and Food Chemistry, 61(3), 579 588. https://doi.org/10.1021/jf3036929

Hu, J.-L., Nie, S.-P., Li, C., \& Xie, M.-Y. (2013). In vitro fermentation of polysaccharide from the seeds of Plantago asiatica L. by human fecal microbiota. Food Hydrocolloids, 33(2), 384-392. https://doi.org/10.1016/j.foodhyd.2013.04.006

Hu, J.-L., Nie, S.-P., Min, F.-F., \& Xie, M.-Y. (2013). Artificial simulated saliva, gastric and intestinal digestion of polysaccharide from the seeds of Plantago asiatica $\mathrm{L}$. Carbohydrate Polymers,

92(2),

$1143-1150$

\section{https://doi.org/10.1016/i.carbpol 2012.10.072}

Kovatcheva-Datchary, P., Nilsson, A., Akrami, R., Lee, Y. S., De Vadder, F., Arora T., Hallen, A., Martens, E., Björck, I., \& Bäckhed, F. (2015). Dietary Fiber-Induced Improvement in Glucose Metabolism Is Associated with Increased Abundance of $\begin{array}{llll}\text { Prevotella. } & \text { Cell } & \text { Metabolism, } & \text { 22(6), }\end{array}$ https://doi.org/10.1016/j.cmet.2015.10.001

Ladirat, S. E., Schuren, F. H. J., Schoterman, M. H. C., Nauta, A., Gruppen, H., \& Schols, H. A. (2014). Impact of galacto-oligosaccharides on the gut microbiota composition and metabolic activity upon antibiotic treatment during in vitro fermentation. FEMS Microbiology Ecology, 87(1), 41-51 https://doi.org/10.1111/1574-6941.12187

Lynnette R. Ferguson, \& Martin Philpott. (2007). Cancer Prevention by Dietary Bioactive Components that Target the Immune Response. Current Cancer Drug Targets, 7(5), 459-464. https://doi.org/10.2174/156800907781386605

Miller, G. L. (1959). Use of Dinitrosalicylic Acid Reagent for Determination of Reducing Sugar. Analytical Chemistry, 31(3), 426-428 https://doi.org/10.1021/ac60147a030

NAVAZESH, M. (1993). Methods for Collecting Saliva. Annals of the New York Academy of Sciences, 694(1 Saliva as a D), 72-77. https://doi.org/10.1111/j.1749. 6632.1993.tb18343.x

Ndeh, D., Rogowski, A., Cartmell, A., Luis, A. S., Baslé, A., Gray, J., Venditto, I., Briggs, J., Zhang, X., Labourel, A., Terrapon, N., Buffetto, F., Nepogodiev, S., Xiao, Y., Field, R. A., Zhu, Y., O’Neill, M. A., Urbanowicz, B. R., York, W. S., ... Gilbert, H. J. (2017). Complex pectin metabolism by gut bacteria reveals novel catalytic functions. Nature, 544(7648), 65-70. https://doi.org/10.1038/nature21725

Neyrinck, A. M., Possemiers, S., Druart, C., Van de Wiele, T., De Backer, F., Cani, P. D., Larondelle, Y., \& Delzenne, N. M. (2011). Prebiotic Effects of Wheat Arabinoxylan Related to the Increase in Bifidobacteria, Roseburia and Bacteroides/Prevotella in Diet-Induced Obese Mice. PLOS ONE, 6(6), e20944. https://doi.org/10.1371/journal.pone.0020944

Ohta, Y., Lee, J.-B., Hayashi, K., Fujita, A., Park, D. K., \& Hayashi, T. (2007). In Vivo Anti-influenza Virus Activity of an Immunomodulatory Acidic Polysaccharide Isolated from Cordyceps militaris Grown on Germinated Soybeans. Journal of Agricultural and Food Chemistry, 55(25), 10194-10199. https://doi.org/10.1021/jif0721287

Oomen, A. G., Hack, A., Minekus, M., Zeijdner, E., Cornelis, C., Schoeters, G. Verstraete, W., Van de Wiele, T., Wragg, J., Rompelberg, C. J. M., Sips, A. J. A. M., \& Van Wijnen, J. H. (2002). Comparison of Five In Vitro Digestion Models To Study the Bioaccessibility of Soil Contaminants. Environmental Science \& Technology, 36(15), 3326-3334. https://doi.org/10.1021/es010204v

Paulson, J. N., Pop, M., \& Bravo, H. C. (2011). Metastats: an improved statistical method for analysis of metagenomic data. Genome Biology, 12(S1), P17.
https://doi.org/10.1186/1465-6906-12-S1-P17

Qasim, M., Saif, U., Waqar, I., Ali, N., Khalid, A. K., Hafeez, M., Dilbar, H. Chandra, K., Bamisope, S. B., Komivi, S, A., Rizwan, M., Shahid, N., Saad, Jan., Liande W. (2020). Characterization of mycotoxins from entomopathogenic fung (Cordyceps fumosorosea) and their toxic effects to the development of asian citrus psyllid reared on healthy and diseased citrus plants. Toxicon, 188, 39-47. https://doi.org/10.1016/j.toxicon.2020.10.012

Ríos-Covián, D., Ruas-Madiedo, P., Margolles, A., Gueimonde, M., de los Reyes Gavilán, C. G., \& Salazar, N. (2016). Intestinal Short Chain Fatty Acids and their Link with Diet and Human Health. Frontiers in Microbiology, 7. https://doi.org/10.3389/fmicb.2016.00185

Roubos-van den Hil, P. J., Schols, H. A., Nout, M. J. R., Zwietering, M. H., \& Gruppen, H. (2010). First Characterization of Bioactive Components in Soybean Tempe That Protect Human and Animal Intestinal Cells against Enterotoxigenic Escherichia coli (ETEC) Infection. Journal of Agricultural and Food Chemistry, 58(13), 7649-7656. https://doi.org/10.1021/jf101379y

Saari, H., Halinen, S., Ganlöv, K., Sorsa, T., \& Konttinen, Y. (1997). Salivary mucous glycoprotein MG1 in Sjögren's syndrome. Clinica Chimica Acta, 259(1-2), 83-96. https://doi.org/10.1016/S0009-8981(96)06464-9

Schloss, P. D., Westcott, S. L., Ryabin, T., Hall, J. R., Hartmann, M., Hollister, E. B., Lesniewski, R. A., Oakley, B. B., Parks, D. H., Robinson, C. J., Sahl, J. W., Stres, B., Thallinger, G. G., Van Horn, D. J., \& Weber, C. F. (2009). Introducing mothur: OpenSource, Platform-Independent, Community-Supported Software for Describing and Comparing Microbial Communities. Applied and Environmental Microbiology, 75(23), 7537-7541. https://doi.org/10.1128/AEM.01541-09

Sonnenburg, E. D., Zheng, H., Joglekar, P., Higginbottom, S. K., Firbank, S. J. Bolam, D. N., \& Sonnenburg, J. L. (2010). Specificity of Polysaccharide Use in Intestinal Bacteroides Species Determines Diet-Induced Microbiota Alterations. Cell, 141(7), 1241-1252. https://doi.org/10.1016/j.cell.2010.05.005

Stokes, Jason R. Davies, G. A. (2007). Viscoelasticity of human whole saliva collected after acid and mechanical stimulation. Biorheology, 44(3), 141-160. https://content.iospress.com/articles/biorheology/bir455

Tremaroli, V., \& Bäckhed, F. (2012). Functional interactions between the gut microbiota and host metabolism. Nature, 489(7415), 242-249. https://doi.org/10.1038/nature11552

van Ruth, S. (2000). Influence of mastication and saliva on aroma release in a mode mouth system. Food Chemistry, 71(3), 339-345. https://doi.org/10.1016/S0308 8146(00)00186-2

Wu, G. D., Chen, J., Hoffmann, C., Bittinger, K., Chen, Y.-Y., Keilbaugh, S. A., Bewtra, M., Knights, D., Walters, W. A., Knight, R., Sinha, R., Gilroy, E., Gupta, K. Baldassano, R., Nessel, L., Li, H., Bushman, F. D., \& Lewis, J. D. (2011). Linking Long-Term Dietary Patterns with Gut Microbial Enterotypes. Science, 334(6052), 105-108. https://doi.org/10.1126/science.1208344

Wu, T., Guo, Y., Liu, R., Wang, K., \& Zhang, M. (2016). Black tea polyphenols and polysaccharides improve body composition, increase fecal fatty acid, and regulate fat metabolism in high-fat diet-induced obese rats. Food \& Function, 7(5), 2469-2478 https://doi.org/10.1039/C6FO00401F

Xu, R., Ye, H., Sun, Y., Tu, Y., \& Zeng, X. (2012). Preparation, preliminary characterization, antioxidant, hepatoprotective and antitumor activities of polysaccharides from the flower of tea plant (Camellia sinensis). Food and Chemical Toxicology, 50(7), 2473-2480. https://doi.org/10.1016/j.fct.2011.10.047

Ye, Z., Wang, W., Yuan, Q., Ye, H., Sun, Y., Zhang, H., \& Zeng, X. (2016). BoxBehnken design for extraction optimization, characterization and in vitro antioxidan activity of Cicer arietinum L. hull polysaccharides. Carbohydrate Polymers, 147, 354 364. https://doi.org/10.1016/j.carbpol.2016.03.092

Zambell, K. L., Fitch, M. D., \& Fleming, S. E. (2003). Acetate and Butyrate Are the Major Substrates for De Novo Lipogenesis in Rat Colonic Epithelial Cells. The Journal of Nutrition, 133(11), 3509-3515. https://doi.org/10.1093/in/133.11.3509

Zhou, L., Wang, W., Huang, J., Ding, Y., Pan, Z., Zhao, Y., Zhang, R., Hu, B., \& Zeng, X. (2016). In vitro extraction and fermentation of polyphenols from grape seeds (Vitis vinifera) by human intestinal microbiota. Food \& Function, 7(4), 1959-1967. https://doi.org/10.1039/C6FO00032K 